\title{
Surgical stress: Cortisol and anxiety in surgeons, patients, and stretcher-bearers
}

\author{
Ángel A. Casillas-Cruz ${ }^{1}$, Ana G. Gutiérrez-Garcia ${ }^{2}$ and Carlos M. Contreras ${ }^{2,3 *}$ \\ ${ }^{1}$ Centro de Especialidades Médicas del Estado de Veracruz "Dr. Rafael Lucio"; 'Laboratorio de Neurofarmacología, Instituto de Neuroetología, \\ Universidad Veracruzana; ${ }^{3}$ Unidad Periférica Xalapa, Instituto de Investigaciones Biomédicas, Universidad Nacional Autónoma de México, Xalapa. \\ Veracruz, México
}

\begin{abstract}
Introduction: Daily stress can cause detrimentally high circulating levels of cortisol. Although habituation to this response can occur, it does not necessarily mean resilience. The operating room may be a natural site for the study of stress. Objective: The aim of the present study was to compare the impact of surgical stress in three protagonists of the operating room who play different roles: surgeon, patient, and stretcher-bearer. Methods: Twelve triads (patient, stretcher-bearer, and surgeon) of volunteers were selected. Urine samples were taken to determine the level of urinary cortisol as an indicator of stress. The state-trait anxiety inventory (STAl) was applied in all subjects before surgery. Results: The statistical analysis indicated that surgeons had the highest urinary cortisol levels, with no difference in cortisol levels between stretcher-bearers and patients. No differences in scores on the STAl-State (which evaluates the level of anxiety in response to a contingency) were found among the three experimental groups, and the lowest STAl-Trait scores (which evaluate anxiety as a personality trait) were found in surgeons. Conclusion: These data suggest that surgeons, through years of professional practice, develop a certain degree of resilience to perceived anxiety, but this resilience does not prevent the elevation of biochemical markers of anxiety. Therefore, although outward signs of anxiety are not manifest, strategies should be implemented to reduce anxiety in this group of professionals.
\end{abstract}

Key words: Surgeons. Stretcher-bearers. Surgery. Stress. Urinary cortisol. Anxiety.

\section{Estrés quirúrgico: cortisol y ansiedad en cirujanos, pacientes y camilleros}

\section{Resumen}

Introducción: El estrés cotidiano puede causar efectos nocivos relacionados con niveles circulantes elevados de cortisol y aunque pueda ocurrir habituación, no necesariamente significa resiliencia. Es posible que el quirófano sea un sitio natural para el estudio del estrés. Objetivo: Se comparó el efecto del estrés quirúrgico en tres protagonistas con diferentes roles. El paciente, el camillero y el cirujano, antes del evento quirúrgico. Métodos: Se seleccionaron 12 tríadas de voluntarios. Se tomaron

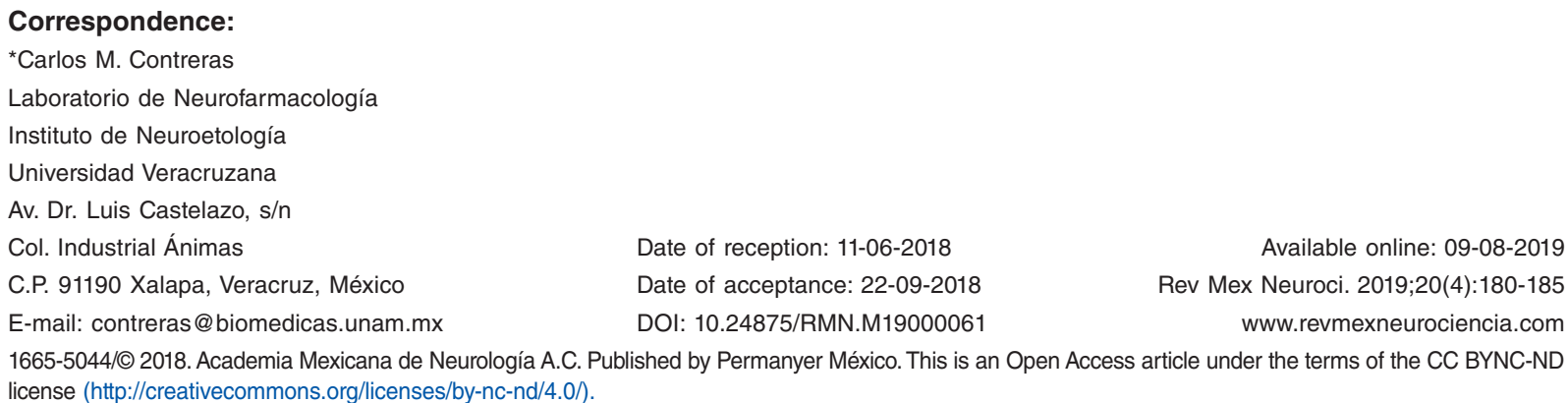

Date of reception: 11-06-2018

Date of acceptance: 22-09-2018 DOI: 10.24875/RMN.M19000061

Available online: 09-08-2019 Rev Mex Neuroci. 2019;20(4):180-185 www.revmexneurociencia.com 
muestras de orina para determinar el nivel del cortisol urinario como indicador de estrés y el Inventario de Ansiedad Rasgo-Estado se aplicó en todos los sujetos en la primera medición previa a la cirugía. Resultados: El análisis estadístico indicó que los niveles urinarios más altos de cortisol correspondieron a los cirujanos y no hubo diferencias entre los camilleros y los pacientes. Mientras que no hubo diferencias en los puntajes de IDARE-Estado (que evalúa el nivel de ansiedad en respuesta a alguna contingencia) entre los tres grupos experimentales, el menor puntaje de la escala IDARE-Rasgo (que evalúa la ansiedad como rasgo de personalidad) se encontró en los cirujanos. Conclusiones: Lo que estos datos indican es que el grupo de cirujanos a través de sus años de ejercicio profesional ha desarrollado cierto grado de resiliencia a la ansiedad percibida, lo que no impide que sus marcadores bioquímicos de ansiedad se encuentren elevados. Por lo que es recomendable la instrumentación de procedimientos encaminados a reducir la ansiedad (aunque no manifiesta) en este grupo de profesionales.

Palabras clave: Cirujanos. Camilleros. Cirugía. Estrés. Cortisol urinario. Ansiedad.

\section{Introduction}

The quality of life of medical staff can be influenced by stressful situations that are related to daily professional pressures. The life expectancies of obstetrician surgeons and gynecologists are lower than other medical specialists ${ }^{1}$ and they are subjected to greater stress $^{2}$. Pressure is perceived as low among psychiatrists, and the uncertainty factor is high among neurologists $^{3}$. However, adaptive processes may result in some resilience to the impact of sustained stress ${ }^{4,5}$.

The spontaneous release of cortisol into plasma is a preparatory response of the organism that allows adaptation to the environment and support for stress situations ${ }^{6}$. However, the continuous presence of cortisol in plasma may be a risk factor for cardiovascular disease?. Under normal conditions, stress results in allostasis $^{8}$, a normal response of the body to sustained stress in an attempt to regain homeostasis. If the stressful situation is prolonged, then the organism can undergo so-called allostatic overload ${ }^{9}$, which can be detrimental to health.

The operating room can be considered a natural model for studying stress and the body's response to stress. Urinary cortisol levels are modified in stressful situations that are associated with surgery. The surgeon-patient dyad is subjected to different but nonetheless intense stress that is represented by the surgical procedure. The present study investigated cortisol levels and their possible relationship to indicators of anxiety among surgeons, patients, and stretcher-bearers.

\section{Methods}

The present study employed a transversal, quasi-experimental design. Approval of the experimental protocol was obtained from the Research Committee and Ethics Committee of the Center of Medical Specialties of the State of Veracruz "Dr. Rafael Lucio" (CEMEV),
México. Based on the relatively common and safe procedures that were used during surgery, the present investigation was classified by General Health Law and the Official Mexican Standard as Category II. The participants in the study received a detailed explanation of the protocol. Afterward, they signed an informed consent form. The anonymity of all of the participants was rigorously ensured.

\section{Experimental groups}

Three groups were formed, based on non-probabilistic convenience sampling ( $n=12 /$ group), with the common experience of having simultaneously participated in the same surgical event. All of the volunteers were male, solely in an attempt to maintain homogeneity of the sample.

The control group consisted of stretcher-bearers with prior experience in the operating rooms of the hospital. Their primary task was to take the patients to the operating room. The group of patients underwent their first surgical intervention experience. All of the patients had received a diagnosis of inguinal hernia. Under epidural anesthesia, they underwent Lichtenstein's inguinal plasty technique. The group of surgeons had at least 7 years of experience and participated directly in the surgical event. All of the surgeons were certified by the Mexican Council of General Surgery.

In all three groups, participants with a history of metabolic disease, corticosteroid intake in the past 6 months, anxiolytic drug intake in the past 3 months, or a history of adrenal gland disease were excluded from the study.

\section{Sampling and state-trait anxiety inventory (STAI) application}

During surgical procedures, the highest degree of expectation is the preoperative period before surgery. 
The pre-operative period began at 8:00 AM. Stretcher-bearers who tend the stretchers play a relatively passive role compared with surgeons and patients. These stretcher-bearers follow a plan, but they are aware that unexpected events can occur that would expose them to a high degree of stress. For these reasons, we collected urine samples and applied the STAI during the pre-operative period.

\section{Urinary cortisol}

A urine sample was collected in a clean container with volume measurements and without preservatives. The quantitative determination of urinary cortisol was performed using an electrochemiluminescent immunoassay (Elecsys 1010/2010, MODULAR ANALYTICS E170, and COBAS E). The Elecsys apparatus for cortisol analysis is based on the competition principle using a polyclonal antibody that is specifically directed against cortisol. The total duration of the analysis was $18 \mathrm{~min}$. A $20 \mu \mathrm{l}$ sample was incubated with a specific antibody and a labeled ruthenium complex that was derived from cortisol. Depending on the concentration of the factor to be analyzed in the sample and formation of the respective immune complex, the binding site of the labeled antibody is partially occupied by the factor to be analyzed and partially occupied by the ruthenylated hapten. In the second incubation, after adding streptavidin-coated microparticles, binding of the complex to the solid phase occurs through interaction of biotin and streptavidin. The mixture is aspirated into the measuring cell where the microparticles are magnetically captured on the surface of the electrode. The free substances are removed with ProCell. The application of a voltage to the electrode induces chemiluminescent emission that is measured by a photomultiplier. A calibration curve was generated based on two-point calibration and a curve that was obtained from the bar code of the reagent. The reference values for cortisol that were used in the CEMEV and established by Bayer Diagnostics were in the range of 28.5-213.7 g/dl (78.6-589.6 nmol/L).

\section{STAI}

The STAI (n.b., the IDARE is the translated and validated version that is used in Mexico) ${ }^{10}$ was previously applied successfully among participants of the surgical procedure $^{11}$. The STAI consists of two self-report scales that are designed to measure anxiety as a present state of anxiety (STAI-S [IDARE-E]) and a trait or personality characteristic (STAI-T [IDARE-R]). The STAI-S measures symptoms of anxiety that a person experiences under a specific situation. The STAI-T measures the frequency with which people usually experience anxiety symptoms as a personality trait. Both scales consist of 20 items that are scored on a Likert scale with four options that range from "not at all" to "too much." The STAI has high consistency, validity, and reliability (Cronbach's $\alpha=0.83$ for the STAI-T subscale and 0.92 for the STAI-S subscale), in which its elements and scales are closely related to the constructs of the instrument. The scores are classified as the following: 20-31 (very low anxiety), 32-43 (low anxiety), 44-55 (moderate anxiety), 56-67 (high anxiety), and 68-80 (very high anxiety).

Both the stretcher-bearers and surgeons completed the STAI during the pre-operative period while being comfortably seated. The patients completed the STAI in their bed before taking any medication as part of balanced anesthesia, with the exception of analgesics when indicated.

\section{Statistical analysis}

The urinary cortisol data and scores on the two STAI subscales did not follow a parametric distribution; therefore, the results were compared using KruskalWallis nonparametric analysis of variance (ANOVA; Statistica 7, Statsoft), followed by the Wilcoxon post hoc test. Values of $p \leq 0.05$ were considered statistically significant. The Wilcoxon test was chosen due to its ability to compare pairs of data that follow a nonparametric distribution. The results are expressed as the mean \pm standard error of the mean. The graphs were generated using Kaleidagraph 4.0 software.

\section{Results}

The ages of the subjects in the study were not significantly different among groups $\left(\mathrm{H}^{2}=3.465, \mathrm{p}<0.177\right)$. The mean age of the stretcher-bearers was $38.1 \pm$ 2.907 years (range: $25-50$ years). The mean age of the surgeons was $44.3 \pm 1.884$ years (range: $36-50$ years). The mean age of the patients was $39.8 \pm 2.396$ years (range: 28-50 years). The surgeons had a mean of $16.0 \pm 1.969$ years of professional experience (range: 7-24 years).

\section{Urinary cortisol}

Significant differences were found in urinary cortisol levels among groups $\left(\mathrm{H}_{2}=7.564, \mathrm{p}<0.023\right)$. The lowest cortisol level was found in the group of 
stretcher-bearers. Urine from patients and surgeons contained higher urinary cortisol levels, which were significantly different between surgeons and stretcher-bearers (Fig. 1).

\section{STAI-S}

The Kruskal-Wallis test showed that the scores on the STAI-S were not significantly different among the three groups $\left(\mathrm{H}_{2}=4.598, \mathrm{p}=0.100\right)$. The Wilcoxon post hoc test, which was used to compare data by pairs, detected a significant difference (Fig. 2), in which the group of patients had the highest scores on the STAI-S.

\section{STAI-T}

The Kruskal-Wallis test indicated significant differences in STAI-T scores among the three groups $\left(\mathrm{H}_{2}=6.333, \mathrm{p}<0.042\right)$. The surgeons had the lowest STAI-T scores (Fig. 3).

\section{Discussion}

The aim of the present study was to measure and compare urinary cortisol and anxiety levels in individuals who were subjected to surgical stress (stretcher-bearers, patients, and surgeons) before the surgical event. The highest concentration of urinary cortisol was found in surgeons. The patients had slightly higher STAI-S scores. The surgeons had the lowest STAI-T scores.

The measurement of urinary cortisol was performed in the $1^{\text {st }} \mathrm{h}$ of the morning. In general, the lowest levels of plasma cortisol are detected by midnight, with an abrupt increase in cortisol levels on awakening ${ }^{12}$. This diurnal increase in cortisol levels is associated with the sleep-wake cycle and consists of an increase in plasma cortisol within the $1^{\text {st }} \mathrm{h}$ after awakening, surpassing the previous level at midnight by $50 \%$ and lasting for at least $1 \mathrm{~h}^{13}$. This diurnal increase is independent of most daily habits ${ }^{12}$ and considered an adaptive vestige ${ }^{14}$ that prepares the individual for everyday contingencies. By the time of the present study (8:00 AM), the cortisol measurements may have still reflected this circadian activity of cortisol levels and thus a preparatory response to stress. The stretcher-bearers had the lowest cortisol levels, which may be related to the burden of stress to which they would be subjected. The stretcher-bearer group is presumably less stressed than patients and surgeons. Cortisol has been considered a marker of stress ${ }^{15}$, considering other markers that are

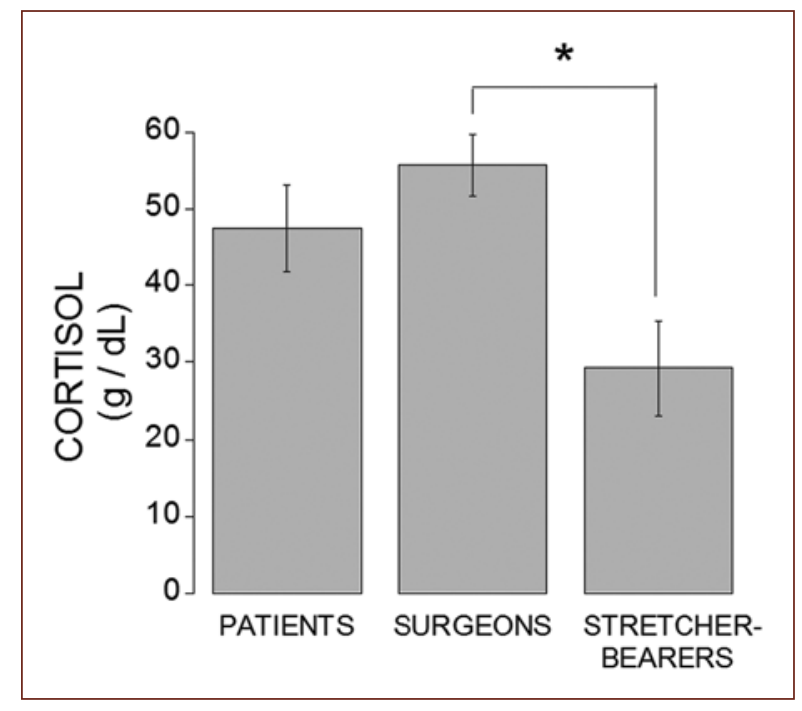

Figure 1. Urinary cortisol. Significant differences were found between surgeons and stretcher-bearers ( $^{*} p<0.007$, Wilcoxon test). The highest levels of urinary cortisol were found in the group of surgeons.

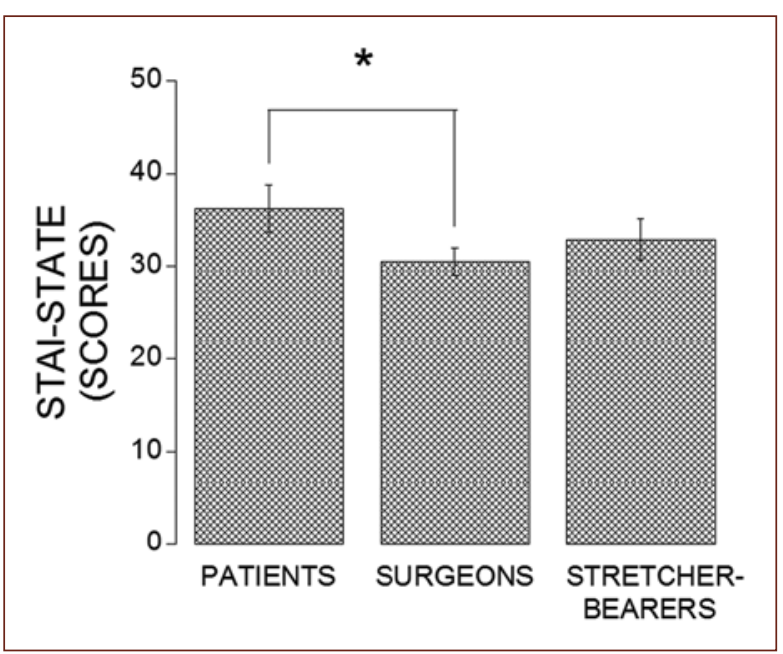

Figure 2. State-trait anxiety inventory-S scores. The nonparametric analysis of variance indicated no signific ant differences among groups. The Wilcoxon post hoc test detected higher scores in patients than in surgeons $\left({ }^{*} p<0.008\right)$, with no significant difference between patients and stretcher-bearers or between surgeons and stretcher-bearers.

related to the activity of the autonomic nervous system, mainly catecholamines and their derivatives. In the present study, we did not evaluate activity of the autonomic nervous system. Although there was a significant difference among groups, the levels of urinary cortisol 


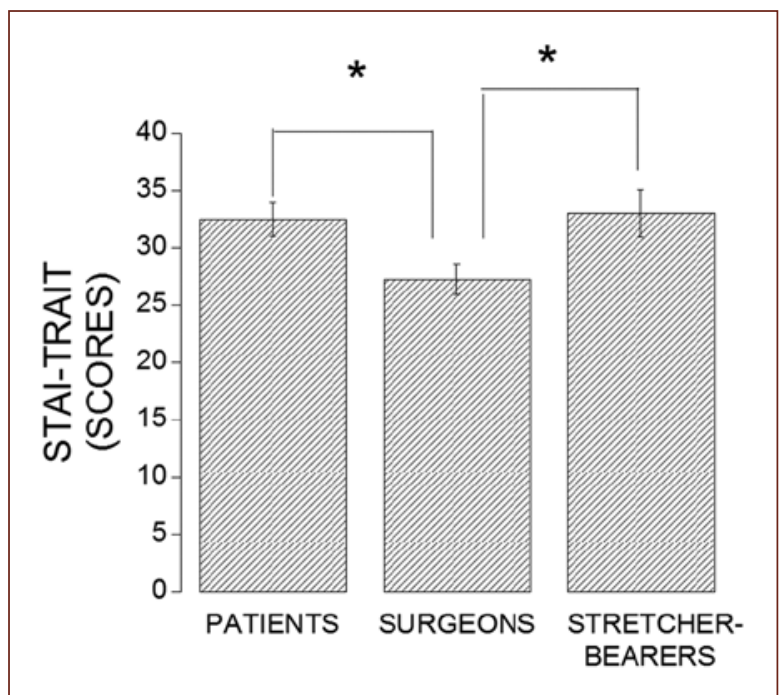

Figure 3. State-trait anxiety inventory-T. Significant differences were found among groups. The surgeons had lower scores than patients $\left({ }^{*} p<0.01\right.$, Wilcoxon test) and stretcher-bearers $\left({ }^{*} p<0.02\right.$, Wilcoxon test).

that was found in the present study were within normal limits in the three groups. The highest concentration of cortisol was found in the group of surgeons.

When confronting a threatening situation, the first components that the individual faces are anxiety and fear. To successfully cope with the situation, a fundamental aspect is learning, which gives rise to an emotional process that ultimately leads to the choice of the best coping response. Emotional memory allows an individual to recognize signs of the environment and compare them with previous experiences to select the most appropriate response to resolve the threatening situation ${ }^{16,17}$. Both processes, learning, and selection of the best response, appear to be regulated by portions of the temporal and frontal lobes and deeper structures, such as the hippocampus and amygdala and their connections to the prefrontal and orbitofrontal cortices ${ }^{18-21}$, among other connections ${ }^{22}$. Cortisol can regulate interconnections between the amygdala and medial prefrontal cortex, in which high levels of cortisol exert a strong negative action on these connections ${ }^{23}$. In the present study, cortisol levels fell within the physiological range, and these levels may be related to a healthy response of the organism. The actions of cortisol mediate suppressive actions in some cases and preparatory actions in others ${ }^{24,25}$.

Natural stress improves immune function, but prolonged stress is associated with a deregulatory action of the immune system and promotes the inflammatory process $^{26}$. Despite some beneficial actions of cortisol, a prolonged increase above certain levels can produce negative effects on the body. Some negative effects include high plasma glucose concentrations, high blood pressure, high fluid retention, muscle weakness, obesity, and extreme fatigue.

The activation of regulatory structures of the emotional response and response to threatening situations depend on such factors as the nature of the stressor, the gender of the subject, and particularly prior experience $^{27}$. In medical students, low levels of cortisol are detected during the day, and high levels occur during the afternoon on the day of scholastic tests and remain elevated even after the test, indicating some adaptive capacity ${ }^{28}$.

The STAI has been successfully applied among surgeons, demonstrating its sensitivity to the detection of anxiety and showing that stress can produce problems with surgical execution even in a surgical simulator ${ }^{29}$ and even after "mental" training that is used to reduce stress in young surgeons ${ }^{30}$. In another study that explored changes in autonomic activity, a strong correlation was found between high levels of autonomic activity and high anxiety scores on the STAI ${ }^{11}$. In the present study, the scores on the STAI-S and STAI-T indicated that all three groups had very low anxiety to low anxiety, although the group of surgeons had the lowest scores on the STAI-T. Notably, STAI-T measures anxiety as a personality trait. Surgeons seemingly become adapted to the stressful stimulus that is represented by the surgical procedure.

One notable paradox was observed in the present study. The surgeons had the highest levels of cortisol while also having the lowest levels of anxiety on the STAI-T. This indicates that a process of adaptation to the stressful stimulus likely occurred, but cortisol levels remained high. In certain situations and depending on prior experience, a subject can develop resistance to threatening situations and is able to adequately manage such situations, which is known as resilience ${ }^{5}$. In the long term, these adaptive changes are beneficial for the organism and allow for proper responses to threatening situations ${ }^{31}$. A clear example is an individual who is at constant risk ${ }^{32}$, which indicates that in a prolonged stressful situation, the individual is able to adapt to stressful situations and maintain his activity within reasonably acceptable limits.

Surgery is stressful. Although strategies to cope with stress are scarce, establishing structured training for stress management is suggested among surgical students $^{33}$. A study by the American College of Surgeons 
found a positive correlation between the number of hours worked and the presence of burnout, particularly for those who worked more than $80 \mathrm{~h} /$ week $^{34}$. The greatest impact of stress depends on the time of exposure and not necessarily on the stressor itself. Therefore, the inclusion of short periods of rest has been recommended ${ }^{35,36}$. Surgical stress is inevitable, and certain strategies can be developed that minimize perceived stress and maintain work activity within acceptable limits.

\section{Conclusion}

Surgeons experience a considerable degree of stress, reflected by biochemical markers of stress (i.e., cortisol), but they appear to develop resilience and the proper management of anxiety. Nonetheless, this does not exclude the possibility that there can be some degree of damage from high cortisol levels in the long term.

\section{Conflicts of interest}

The authors declare that there are no conflicts of interest in this work.

\section{Acknowledgments}

The authors thank Michael Arends for revising and editing the English of the manuscript.

\section{Funding}

There was no particular funding source for this scientific report.

\section{References}

1. Nishi M, Miyake $H$, Kato $T$, Yamazoe M, Tanaka $E$, Ishii $T$, et al. Life span of Japanese male medical doctors. J Epidemiol. 1999:9:315-9.

2. Hull L, Arora S, Kassab E, Kneebone R, Sevdalis N. Assessment of stress and teamwork in the operating room: an exploratory study. Am J Surg. 2011;201:24-30

3. Tanner G, Bamberg E, Kozak A, Kersten M, Nienhaus A. Hospital physicians' work stressors in different medical specialities: a statistical group comparison. J Occup Med Toxicol. 2015;10:7.

4. McEwen BS. Mood disorders and allostatic load. Biol Psychiatry. 2003; 54:200-7.

5. Rutter M. Implications of resilience concepts for scientific understanding Ann N Y Acad Sci. 2006;1094:1-2.

6. Straub $\mathrm{RH}$. Interaction of the endocrine system with inflammation: function of energy and volume regulation. Arthritis Res Ther. 2014;16:203

7. Poantă L, Crăciun A, Dumitraşcu DL. Professional stress and inflammatory markers in physicians. Rom J Intern Med. 2010;48:57-63.

8. McEwen BS. Physiology and neurobiology of stress and adaptation: central role of the brain. Physiol Rev. 2007;87:873-904.

9. McEwen BS. Stress, adaptation, and disease. Allostasis and allostatic load. Ann N Y Acad Sci. 1998;840:33-44.
10. Marteau TM, Bekker $\mathrm{H}$. The development of a six-item short-form of the state scale of the Spielberger state-Trait anxiety inventory (STAI). Br J Clin Psychol. 1992;31:301-6.

11. Jones $\mathrm{KI}$, Amawi $\mathrm{F}$, Bhalla A, Peacock $\mathrm{O}$, Williams JP, Lund JN, et al Assessing surgeon stress when operating using heart rate variability and the state trait anxiety inventory: will surgery be the death of us? Colorectal Dis. 2015;17:335-41.

12. Wüst $\mathrm{S}$, Wolf $\mathrm{J}$, Hellhammer $\mathrm{DH}$, Federenko I, Schommer N, Kirschbaum $\mathrm{C}$, et al. The cortisol awakening response normal values and confounds. Noise Health. 2000;2:79-88.

13. Pruessner JC, Wolf OT, Hellhammer DH, Buske-Kirschbaum A von Auer K, Jobst S, et al. Free cortisol levels after awakening: a reliable biological marker for the assessment of adrenocortical activity. Life Sci. 1997;61:2539-49.

14. Contreras CM, Gutiérrez-García AG. Cortisol awakening response: an ancient adaptive feature. J Psychiatry Psychiatric Disord. 2018;2:29-40.

15. Kozlov Al, Kozlova MA. Cortisol as a marker of stress. Fiziol Cheloveka. 2014;40:123-36.

16. Contreras CM, Gutiérrez-García AG. Emotional memory and chemical communication. In: Benitez-King G, Cisneros-Berlanga C, editors. The Neurobiological Sciences Applied to Psychiatry: from Genes, Proteins and Neurotransmitters to Behavior. Kerala: research Signpost; 2010. p. 171-88.

17. Gutiérrez-García AG, Contreras CM. Anxiety: an adaptive emotion. In Durbano F, editor. New Insights into Anxiety Disorders. Rijeka: INTECH; 2013. p. 21-37.

18. Gabbott PL, Warner TA, Jays PR, Salway P, Busby SJ. Prefrontal cortex in the rat: projections to subcortical autonomic, motor, and limbic centers. Comp Neurol. 2005;492:145-77.

19. Ghashghaei HT, Barbas H. Pathways for emotion: interactions of prefrontal and anterior temporal pathways in the amygdala of the rhesus monkey. Neuroscience. 2002;115:1261-79.

20. LeDoux JE. Emotion circuits in the brain. Annu Rev Neurosci. 2000; 23:155-84.

21. Zelikowsky M, Hersman S, Chawla MK, Barnes CA, Fanselow MS. Neuronal ensembles in amygdala, hippocampus, and prefrontal cortex track differential components of contextual fear. J Neurosci. 2014;34:8462-6.

22. Phillips ML, Drevets WC, Rauch SL, Lane R. Neurobiology of emotion perception I: the neural basis of normal emotion perception. Biol Psychiatry. 2003;54:504-14

23. Veer IM, Oei NY, Spinhoven $P$, van Buchem MA, Elzinga BM, Rombouts SA, et al. Endogenous cortisol is associated with functional connectivity between the amygdala and medial prefrontal cortex. Psychoneuroendocrinology. 2012;37:1039-47.

24. Sapolsky RM, Romero LM, Munck AU. How do glucocorticoids influence stress responses? Integrating permissive, suppressive, stimulatory, and preparative actions. Endocr Rev. 2000;21:55-89.

25. Sapolsky RM. Stress hormones: good and bad. Neurobiol Dis. 2000; 7:540-2.

26. Dhabhar FS. Effects of stress on immune function: the good, the bad, and the beautiful. Immunol Res. 2014;58:193-210.

27. Dedovic K, D'Aguiar C, Pruessner JC. What stress does to your brain: a review of neuroimaging studies. Can J Psychiatry. 2009:54:6-15.

28. Hulme PA, French JA, Agrawal S. Changes in diurnal salivary cortisol levels in response to an acute stressor in healthy young adults. J Am Psychiatr Nurses Assoc. 2011;17:339-49.

29. Arora S, Sevdalis N, Aggarwal R, Sirimanna P, Darzi A, Kneebone R, et al. Stress impairs psychomotor performance in novice laparoscopic surgeons. Surg Endosc. 2010;24:2588-93.

30. Arora S, Aggarwal R, Moran A, Sirimanna P, Crochet P, Darzi A, et al. Mental practice: effective stress management training for novice surgeons. J Am Coll Surg. 2011;212:225-33.

31. Herman JP, Ostrander MM, Mueller NK, Figueiredo $\mathrm{H}$. Limbic system mechanisms of stress regulation: hypothalamo-pituitary-adrenocortical axis. Prog Neuropsychopharmacol Biol Psychiatry. 2005;29:1201-13.

32. Brown TG, Ouimet MC, Eldeb M, Tremblay J, Vingilis E, Nadeau L, et al. Personality, executive control, and neurobiological characteristics associated with different forms of risky driving. PLoS One. 2016;11:e0150227.

33. Arora S, Sevdalis N, Nestel D, Tierney T, Woloshynowych M, Kneebone R et al. Managing intraoperative stress: what do surgeons want from a crisis training program? Am J Surg. 2009;197:537-43.

34. Balch CM, Shanafelt TD, Dyrbye L, Sloan JA, Russell TR, Bechamps GJ, et al. Surgeon distress as calibrated by hours worked and nights on call. J Am Coll Surg. 2010;211:609-19.

35. Rieger A, Stoll R, Kreuzfeld S, Behrens K, Weippert M. Heart rate and heart rate variability as indirect markers of surgeons' intraoperative stress. Int Arch Occup Environ Health. 2014;87:165-74.

36. Rieger A, Fenger S, Neubert S, Weippert M, Kreuzfeld S, Stoll R, et al. Psychophysical workload in the operating room: primary surgeon versus assistant. Surg Endosc. 2015;29:1990-8. 